06

\title{
Особенности перемещения расплавленных зон в поле структурной неоднородности кремния
}

\author{
(C) А.А. Скворцов, С.М. Зуев, М.В. Корячко, Е.Б. Волошинов
}

Московский политехнический университет

E-mail: SkvortsovAA2009@yandex.ru

\section{Поступило в Редакцию 5 апреля 2017 г.}

Рассмотрены формирование и динамика расплавленных включений $\mathrm{Al}-\mathrm{Si}$ в кремнии (в диапазоне температур 1123-1273 K) в поле градиента концентрации дислокаций. Обнаружено, что расплавленное включение перемещается как целое по механизму „плавление-кристаллизация“: в области с большей концентрацией дислокаций на фронтальной границе наблюдается растворение, а в области с меньшей, на тыльной стороне, - кристаллизация. Экспериментально зафиксированы скорости и энергии активации процесса миграции. Показано, что лимитирующей стадией миграции включений являются процессы плавления-кристаллизации на межфазных границах расплава с матрицей.

DOI: 10.21883/PJTF.2017.15.44869.16814

Образование и динамика расплавленных включений в полупроводниках проявляются при росте кристаллов $[1,2]$, включая зонную перекристаллизацию [3], при легировании [4], а также при тепловой деградации межфазных границ металл-полупроводник [5,6]. Следует отметить, что динамика расплавленных зон в кристаллах возможна и в условиях неоднородного распределения структурных дефектов (вакансии, дислокации). Однако в полупроводниках (в отличие, например, от ионных кристаллов [7]) подобные вопросы практически не рассмотрены, хотя подсистема структурных дефектов в материаловедении полупроводников играет в ряде случаев ключевую роль [8-10].

Поэтому далее будут рассмотрены вопросы образования и направленной миграции расплавленных зон типа металл-полупроводник в монокристаллическом кремнии в присутствии поля градиента плотности дислокаций. 

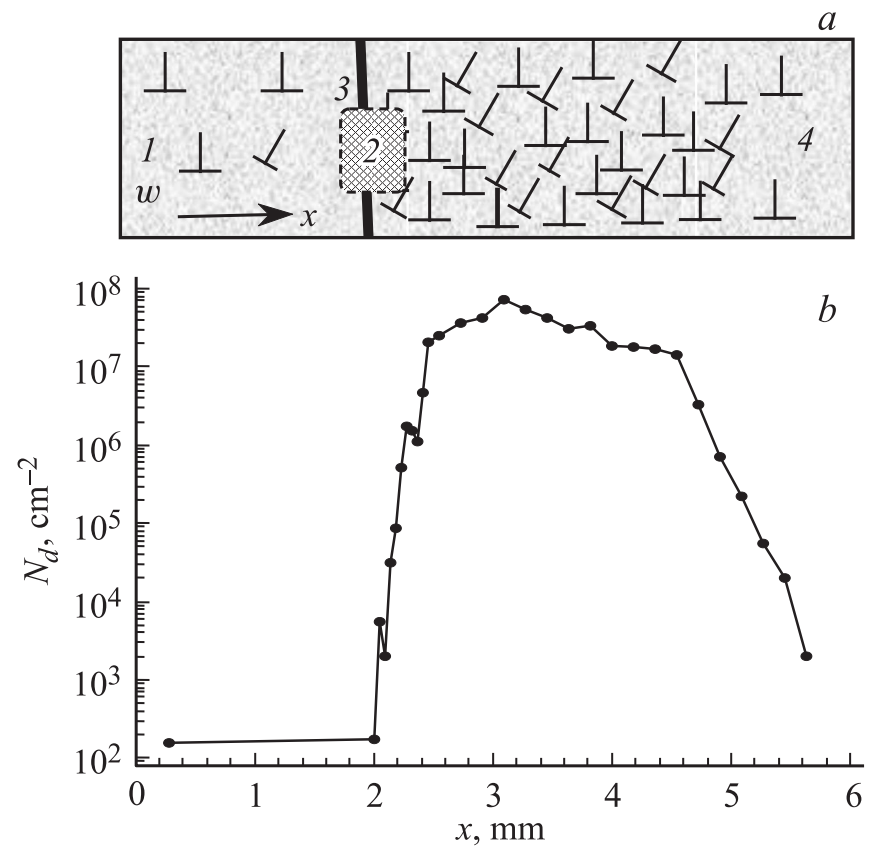

Рис. 1. $a-$ схема формирования и миграции расплавленного включения в поле градиента концентрации дислокаций: 1 - образец монокристаллического кремния плотностью дислокаций $N_{d} \sim 10^{3} 1 / \mathrm{cm}^{2} ; 2-$ расплавленное включение; 3 - пленка алюминия; 4 - образец монокристаллического кремния $N_{d} \sim 10^{4}-10^{7} 1 / \mathrm{cm}^{2} . b$ - распределение $N_{d}$ по длине составного образца.

Известно $[7,8,11]$, что макроскопическое включение в кристалле может перемещаться как целое либо в поле градиента химического потенциала, поддерживаемого извне, либо под влиянием сил, внутренних по отношению к кристаллу. При этом влияние структурной неоднородности кристалла, как правило, не рассматривается. Однако это можно делать далеко не всегда, и часто движение макроскопических включений в кристаллах может происходить в поле структурной неоднородности, в том числе дислокационной.

Рассмотрим макроскопическое включение (рис. $1, a)$, расположенное в матрице вдоль неоднородного распределения дислокаций (рис. $1, b$ ).

Письма в ЖТФ, 2017, том 43, вып. 15 
Как показано в [7], на диаметрально противоположных участках поверхности, ограничивающей включение радиуса $R$, плотность дислокаций отличается на величину $\left.\Delta N_{d}=\left(d N_{d} / d x\right) \ell\right)$. При этом рассмотрим наиболее распространенный случай, когда характерный размер включения $\ell=2 R$ в направлении $x$ существенно превосходит среднее расстояние между дислокациями, т. е. при $\ell>>N_{d}^{-1 / 2}$.

Ситуация, подобная изображенной на рис. $1, a$, может реализоваться в условиях, когда диффузионная подвижность атомов матрицы в твердой фазе мала (например, при отсутствии внешних силовых воздействий). В случае, когда вещество матрицы растворимо во включении, через объем включения возможен облегченный диффузионный путь транспорта вещества $[7,11,12]$.

Известно [7,12], что различия в плотности дислокаций $\Delta N_{d}$ определяет изменение химических потенциалов атомов $\Delta \mu_{k}=\varepsilon \omega_{k} \Delta N_{d}$, где $\varepsilon-$ энергия дислокации единичной длины, $\omega_{k}-$ атомный объем в твердой фазе. Величина $\Delta \mu_{k}=\varepsilon \omega_{k}\left(\partial N_{d} / \partial x\right) 2 R$ в обсуждаемом случае является движущей силой растворения вещества матрицы на „лобовой“ и осаждения на „тыльной“ поверхностях включения или, что то же, смещения включения как целого с некоторой скоростью $w$.

В работе [7] показано, что размерная зависимость скорости миграции расплавленной зоны в этом случае имеет вид

$$
w=\frac{\bar{\beta} c D_{i}}{c D_{i}+\bar{\beta} \omega_{i} k T \ell}\left(\varepsilon \omega_{k} \frac{\partial N_{d}}{\partial x} \ell-\Delta \mu^{*}\right),
$$

где $\Delta \mu^{*}=\Delta \mu_{p}^{*}+\Delta \mu_{0}^{*} ; \Delta \mu_{p}^{*}, \Delta \mu_{0}^{*}-$ скачки химического потенциала на растворяющейся и растущей поверхностях включения; $\bar{\beta}=\frac{\beta_{0} \beta_{p}}{\beta_{0}+\beta_{p}}$; $\beta_{0}, \beta_{p}$ - нормированные на $k T$ удельные потоки растворения и кристаллизации; $D_{i}, \omega_{i}, c-$ коэффициент диффузии, атомный объем и концентрация в объеме включения.

Из (1) следует, что при $\varepsilon \omega_{k} \frac{\partial N_{d}}{\partial x} \ell \leqslant \frac{\Delta \mu^{*}}{\varepsilon \omega_{k}}$ включение двигаться не будет. Оценки, проведенные в [7], показывают, что смещаться будут только те включения, у которых плотность дислокаций на лобовой и тыльной поверхностях отличается на величину $\Delta N_{d} \sim 10^{6}-10^{8} \mathrm{~cm}^{-2}$.

Проанализируем уравнение (1) в предельном случае, когда лимитирующей стадией являются процессы растворения-кристаллизации $\left(c D_{i} \gg \bar{\beta} \omega_{i} k T \ell\right)$ :

$$
w=\bar{\beta} \omega_{k}\left(\varepsilon \omega_{k} \frac{\partial N_{d}}{\partial x} 2 R-\Delta \mu^{*}\right)
$$

Письма в ЖТФ, 2017, том 43, вып. 15 


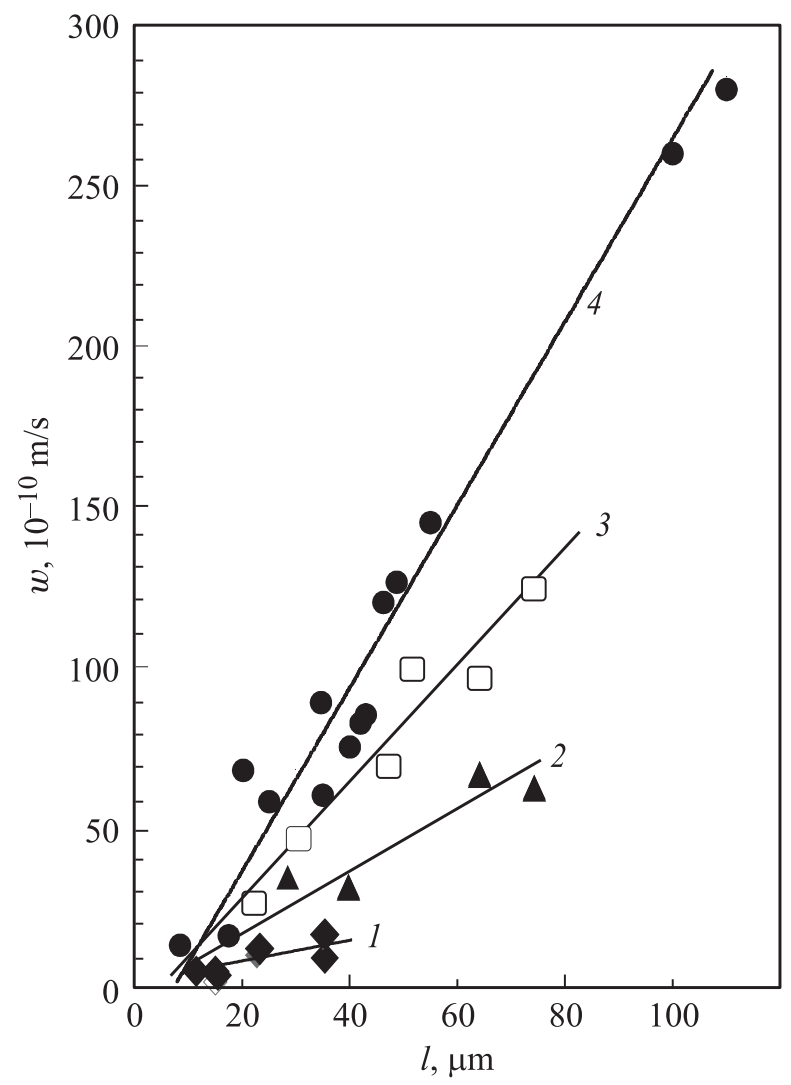

Рис. 2. Размерная зависимость скорости движения включений при различных температурах, K: 1 - 1123, $2-1173,3-1223,4-1273$.

Таким образом, в „кинетическом“ режиме скорость включения зависит линейно от его размера.

В случае диффузионного контроля $\left(c D_{i} \ll \bar{\beta} \omega_{i} k T \ell\right)$, когда процесс миграции лимитируется диффузией, уравнение (1) имеет вид

$$
w=\frac{c D_{i} \omega_{k}}{\omega_{i} k T}\left(\varepsilon \omega_{k} \frac{\partial N_{d}}{\partial x}-\frac{\Delta \mu^{*}}{\ell}\right) .
$$

Письма в ЖТФ, 2017, том 43, вып. 15 

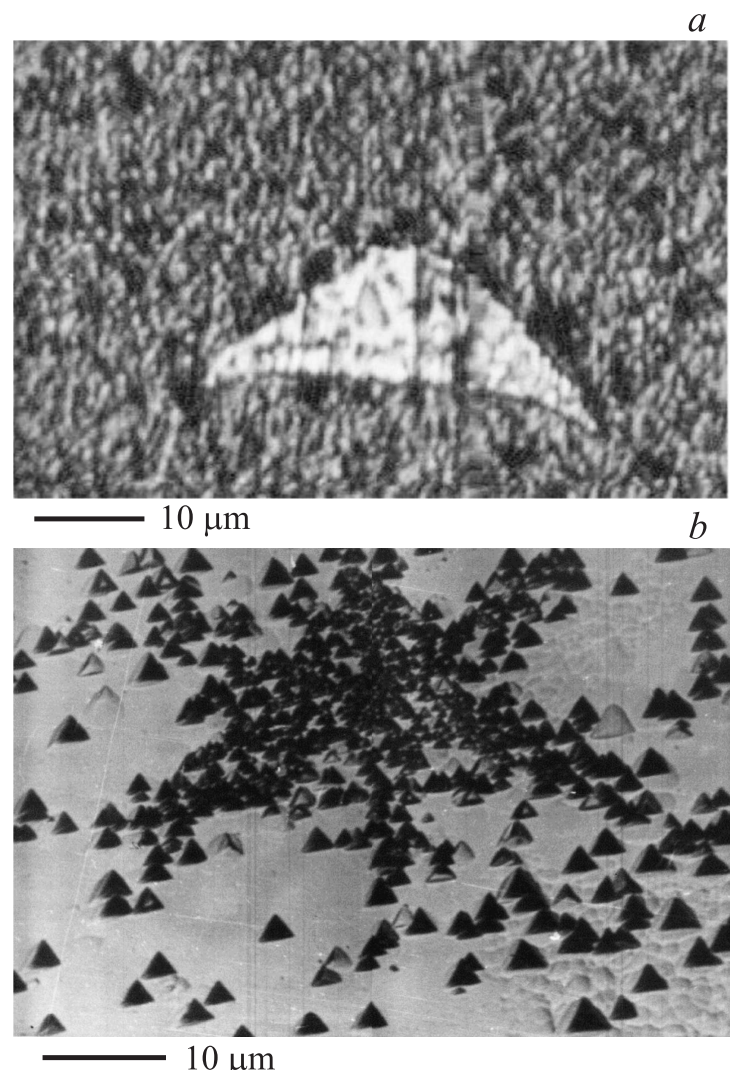

Рис. 3. Фотография закристаллизованного включения $\mathrm{Al}-\mathrm{Si}(a)$ и дислокационной структуры, возникающей после кристаллизации зоны $(b)$.

Экспериментальная проверка осуществлялась на монокристаллическом кремнии $n$-типа размером $3 \times 3 \times 15 \mathrm{~mm}(\rho=1 \Omega \cdot \mathrm{cm})$. Градиент концентрации дислокаций создавался изгибом образцов при температуpe $1323 \mathrm{~K}$. Полученные образцы разрезались в месте максимального градиента, после чего между торцами образцов зажималась тонкая пленка алюминия и производился отжиг в инертной атмосфере в диапазоне температур $T=800-1100^{\circ} \mathrm{C}$. Методика проведения опытов 
детально изложена в [11]. Единственным отличием было наличие поля дислокаций, плотность которых выявлялась по ямкам травления.

Как и ранее [11], возникновение расплавленных зон в объеме матрицы при отжиге в диапазоне температур (1123-1273 K) связано с процессами сплавообразования примесной металлической пленки с монокристаллом на границе раздела металл-полупроводник (при температурах выше температуры плавления эвтектики $\mathrm{Al}-\mathrm{Si}$, которая составляет $850 \mathrm{~K})$.

Размер и глубину проникновения включений в матрицу от границы определяли последовательной шлифовкой слоев через каждые 5-10 $\mu \mathrm{m}$ с последующей идентификацией включений при помощи оптического микроскопа. Размер включений после кристаллизации лежал в диапазоне $20-250 \mu \mathrm{m}$.

Типичные результаты исследований приведены на рис. 2. Нетрудно видеть, что размерные зависимости скорости движения включений в диапазоне температур $(1100-1300 \mathrm{~K})$ носят линейный характер, что свидетельствует в пользу кинетического режима движения включений. Полученные энергии активации $\left(E_{a}=0.9-1.5 \mathrm{eV}\right)$ по температурным зависимостям скорости миграции включений разного размеpa $(20-60 \mu \mathrm{m})$ также свидетельствуют в пользу лимитирующих механизмов, связанных с процессами плавления-кристаллизации в процессе движения зоны в поле градиента концентрации дислокаций.

Следует также подчеркнуть, что процессы кристаллизации на тыльной стороне включения могут приводить к образованию новых дислокаций вокруг включения, что может существенно изменить $N_{d}$ по сравнению с первоначальным распределением (рис. 3).

Таким образом, в работе рассмотрена динамика миграции расплавленных включений $\mathrm{Al}-\mathrm{Si}$ в монокристаллическом кремнии при наличии поля структурной неоднородности в виде дислокаций. Показано, что возникающие зоны движутся в поле градиента концентрации дислокаций в область с большей концентрацией. Экспериментально зафиксированы скорости и энергии активации процесса миграции. Показано, что лимитирующей стадией миграции зон являются процессы плавления-кристаллизации на межфазных границах расплава с матрицей.

Работа выполнена в рамках проекта Министерства образования и науки РФ, № 8.5171.2017/БЧ.

Письма в ЖТФ, 2017, том 43, вып. 15 


\section{Список литературы}

[1] Abe T., Takahashi T., Shirai K. // J. Cryst. Growth. 2017. V. 459. P. 87-94.

[2] Talanin V.I., Talanin I.E., Ustimenko N.P. // Crystallogr. Reports. 2012. V. 57. Iss. 7. P. 898-902.

[3] Грабов В.М., Комаров В.А., Каблукова Н.С. и др. // Письма в ЖТФ. 2015. T. 41. B. 1. C. 20-27.

[4] Demireva D., Ziffudin L., Barbova M. // Semicond. Sci. Technol. 1998. V. 13. Iss. 11. P. 1290-1293.

[5] Skvortsov A.A., Zuev S.M., Koryachko M.V., Glinskiy V.V. // Microelectron. Int. 2016. V. 33. Iss. 2. P. 102-106.

[6] Сквориов А.А., Каленков С.Г., Корячко М.В. // Письма в ЖТФ. 2014. Т. 40. B. 18. C. $24-32$.

[7] Дзюба А.С. // ФТТ. 1977. Т. 19. V. 1. С. 78-82.

[8] Costa I., Brito M.C., Gaspar G. et al. // Semicond. Sci. Technol. 2013. V. 28 (12). P. 125023 (1-6).

[9] Eslamian M., Saghir M.Z. // Int. J. Therm. Sci. 2011. V. 50. Iss. 7. P. 1232-1242.

[10] Wang Y., Kakimoto K. // J. Cryst. Growth. 2003. V. 247. Iss. 1-2. P. 1-12.

[11] Skvortsov A.A., Khripach N.A., Zaletov D.V., Pshonkin D.E. // Res. J. Pharmaceut. Biol. Chem. Sci. 2016. V. 7. Iss. 6. P. 998-1003.

[12] Гегузин Я.Е., Кривоглаз М.А. Движение макроскопических включений в твердых телах. М.: Металлургия, 1971. 344 с. 